\title{
Microbiota-induced T cells block allergic inflammation
}

$\mathrm{ROR}_{\mathrm{T}} \mathrm{t}^{+} \mathrm{T}$ cell populations ... negatively regulate type 2 immunity
Disturbing the microbiota early in life is associated with a greater risk of developing allergic disorders. The reasons for this have not been clear, but a study in Science now suggests that the intestinal microbiota restrains type 2 immune responses by inducing the development of ROR $\gamma$ t-expressing T cells.

The microbiota has previously been shown to support the development of ROR $\gamma \mathrm{t}^{+} \mathrm{T}$ cell populations, such as $\mathrm{T}$ helper $17\left(\mathrm{~T}_{\mathrm{H}} 17\right)$ cells and

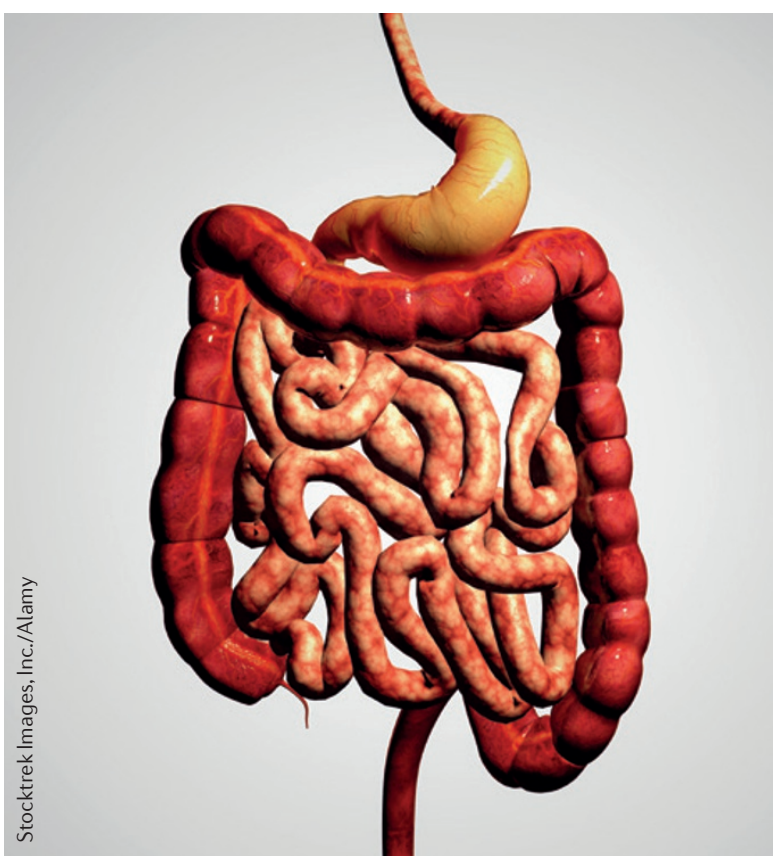

a subset of forkhead box $\mathrm{P} 3$ protein (FOXP3)-expressing regulatory $\mathrm{T}$ $\left(\mathrm{T}_{\mathrm{Reg}}\right)$ cells. Using dual reporter mice, the authors found that the majority of ROR $\gamma \mathrm{t}^{+} \mathrm{T}$ cells in the colon co-express FOXP3 and showed that they are ROR $\gamma \mathrm{t}^{+} \mathrm{T}_{\mathrm{Reg}}$ cells. ROR $\gamma \mathrm{t}^{+} \mathrm{T}_{\mathrm{Reg}}$ cell populations were expanded with age in mice but were markedly reduced in germfree or antibiotic-treated mice. By contrast, thymus-derived $\mathrm{T}_{\mathrm{Reg}}$ cells and GATA3 ${ }^{+} \mathrm{T}_{\mathrm{Reg}}$ cells were not reduced in germ-free or antibiotictreated mice. Germ-free mice that were recolonized with microbiota had normal numbers of ROR $\gamma \mathrm{t}^{+}$ $\mathrm{T}_{\text {Reg }}$ cells, confirming that the microbiota supports the generation of these cells. The development of ROR $\gamma \mathrm{t}^{+} \mathrm{T}_{\mathrm{Reg}}$ cells was also found to depend on MHC class II molecules and dendritic cells (DCs), as well as on the STAT3-activating cytokines interleukin-6 (IL-6) and IL-23.

To examine whether these microbiota-induced ROR $\gamma \mathrm{t}^{+} \mathrm{T}_{\mathrm{Reg}}$ cells regulate type 2 immune responses, the authors generated mice with a conditional knockout of the gene encoding ROR $\gamma \mathrm{t}$ in FOXP3 ${ }^{+}$cells. These mice specifically lacked ROR $\gamma \mathrm{t}^{+}$ $\mathrm{T}_{\text {Reg }}$ cells and showed increased frequencies of GATA3 ${ }^{+} \mathrm{T}_{\mathrm{H}} 2$ cells and GATA3 $^{+} \mathrm{T}_{\mathrm{Reg}}$ cells in the intestine. Compared with littermate controls, the ROR $\gamma \mathrm{t}^{+} \mathrm{T}_{\mathrm{Reg}}$ cell-deficient mice developed more severe disease in an oxazolone-induced colitis model, which depends on the type 2 cytokines IL-4 and IL-13. In addition, mice lacking ROR $\gamma \mathrm{t}^{+} \mathrm{T}_{\mathrm{Reg}}$ cells showed greater resistance to a helminth infection. The suppression of $\mathrm{T}_{\mathrm{H}} 2$ cells was not dependent on the production of IL-10 by ROR $\gamma \mathrm{t}^{+}$ $\mathrm{T}_{\text {Reg }}$ cells but instead involved their expression of cytotoxic T lymphocyte antigen 4 (CTLA4); CTLA4 seemed to suppress $\mathrm{T}_{\mathrm{H}} 2$ cell induction by regulating $\mathrm{DC}$ expression of the co-stimulatory molecules CD80 and CD86. Notably, $\mathrm{T}_{\mathrm{H}} 17$ cells were also found to contribute to the suppression of type 2 immune responses, as $\mathrm{T}_{\mathrm{H}} 2$ cell populations were further expanded in mice with a complete ROR $\gamma t$ deficiency compared with mice with a $\mathrm{T}_{\mathrm{Reg}}$ cell-specific ROR $\gamma \mathrm{t}$ deficiency.

The authors suggest that reduced microbial exposure prevents the development of ROR $\gamma \mathrm{t}^{+} \mathrm{T}$ cell populations that have the capacity to negatively regulate type 2 immunity; this might explain why allergies are on the rise in industrialized nations.

Yvonne Bordon

ORIGINAL RESEARCH PAPER Ohnmacht, C. et al The microbiota regulates type 2 immunity through ROR $\gamma \mathrm{t}^{+}$T cells. Science http://dx.doi.org/10.1126/ science.aac4263 (2015) 